\title{
Revisiting the Financial Year in India
}

\author{
Asit Ranjan Mohanty \\ Xavier University and Chair Professor of Centre of Fiscal Policy and Taxation
}

Avipsa Mohanty

Centre of Fiscal Policy and Taxation, Xavier University, Bhubaneswar

\begin{abstract}
The Ministry of Finance, Government of India, has recently constituted an expert committee to look into the feasibility of changing the Financial Year in India. This has rekindled the debate which is now a hundred and fifty years old. A Financial Year is a period of 12 months used for estimating and analyzing the government's financial accounts. The present financial year in India runs from the 1st April to the 31st March of the following year. It was adopted in 1867 on the grounds of aligning it with the British practice. The Financial Year has been subject to debate for so long considering the fact that it was adopted without taking into consideration local/ Indian customs. The current debate necessitates a re-evaluation of the Financial Year in India. This study has attempted to analyze the issue of changing financial year in India considering the international practices. After evaluating the current dynamics of India, this study suggests for a status quo.
\end{abstract}

Keywords: Financial Year, Budget, Monsoon, India. JEL Classification: H61, Q58, 053.

\section{BACKGROUND}

The "Budget System" in India can be traced back to the second half of the 19th century. It was introduced in India by James Wilson, first Finance Member of the Council of the British Crown. James Wilson gave the first budget speech on the 18th February 1860. The Budget System necessitated that financial estimates of each year be prepared, presented and approved by the Legislative Council. The design of the scheme was spelled out in the Financial Resolution of 7 th April 1860. The Budget System in India is therefore, almost 156 years old.

The Mutiny of 1858 had entailed great financial catastrophe. The expenditures of the Government of India outweighed the revenues, 1853 onwards. Deficits accumulated and ran into several million pound sterlings. The chronic debt situation was a consequence of the abnormal military expenditure made during the mutiny. The disequilibrium failed to ease off. The Government of India resorted to borrowing. Consequently, the public debt and the interest payments to be made on the same, mounted. Between April 1857 and April 1860, the public debt of India increased by a massive $£ 39$ million. The rampant increase in debt necessitated an immediate retrenchment of the military expenditure at the earliest.

The mutiny swept away those systems and institutions which had outlived their usefulness. The new government under the aegis of the British Crown faced the problem of reconstruction of financial system. As the political nature of the Crown overpowered the commercial preoccupations of the East India Company, the defects in the old system of finance surfaced. The budgeting of income and expenditure was imprudent and the accounts ran into mass confusion and consequent to the mutiny the entire system of financial administration became 
deranged. Thereafter, financial administration was overhauled. A new system of budgets was enforced; the relationship with the Home(who is home govt) government saw significant changes and changes in the system of taxation were introduced.

The Crown took over the responsibility of the debts and liabilities of the Company vide the Government of India Act 1858. The Secretary of State was entrusted with the responsibility of supervising the expenditure of revenues of the government. His approval was mandatory for the purpose of grants and appropriation of funds. It was mandated that the revenue and expenditure of British India was to be presented in the Parliament on an annual basis.

To ensure transparency and prudence, an auditor of Indian finances was appointed for independent scrutiny of the finances. He was given the authority to call upon the Secretary of State for producing papers related to Indian finances. He could also examine the Government officers in the United Kingdom in relation to Indian accounts. Accordingly, the Secretary of the State was legally bound to present the statement of position of Indian finances in both the houses, annually. The act entailed the annual Indian Budget debate. But the Parliament was rarely called upon to approve the proposed expenditure rather it was merely informed about the accounts of the previous year and current year's revised estimates. Nevertheless, this annual debate kept the Parliament apprised of the Indian affairs.

Meanwhile, the Secretary of State, Sir Charles Wood, having realized the gravity of the financial situation, sent out Hon. James Wilson as Finance Member to India. A financier of great repute, Wilson soon comprehended that the Government had borrowed without restraint and the way out was through the drastic retrenchment and increased taxation.

Only three months after his arrival in India, James Wilson presented his first and only budget on 18th February 1860. This budget detailed the financial situation of the country and listed measures to bring about financial equilibrium. The first Budget expressed the faith Wilson had on the resources of the nation and the ability of the people to develop them to address the urgency in the finances. The document contained multiple taxation proposals. The two principal measures introduced by him were: a tax on incomes above Rs. 200 and a license duty on trades and professions. He also put forth significant measures to reduce military expenditure. Subsequently, Income Taxes Act was enforced amid great apprehension while the license duty on trades and profession was kept in abeyance.

Wilson was a fine architect of finances. He wasn't satisfied with the halfmeasures. His intentions of thorough financial reorganization of India were succinct. He died only after eight months of his arrival in India leaving behind his unfinished tasks at the hands of his successor Samuel Laing.

James Wilson is credited with the establishment of the Budget System in India. The Budget is an annual financial statement concerning estimates of revenues and expenditures for the forthcoming year. The budget document highlights the financial policy of the government. The Budget has been presented before the Parliament every year since 1860. It is from the annual nature of the budgets that the concept of the Financial Year (budget year) emerges. A financial year is a period of 12 months used for estimating and analyzing the government's financial accounts.

The study is designed as follows.Section 2 of the present study elaborates on the various financial years followed by the countries across the world. Section 3 concerns the various 
issues and debates concerning financial year in India today. Section 4 details the author's suggestions. And finally, Section 5 concludes with policy suggestions.

\section{INTERNATIONAL SCENARIO}

The financial year commences on 1st January for Malaysia, Denmark, China, Austria, Belgium, Brazil and Sri Lanka. It commences on the 1st of April for Japan, U.K., Canada, India and Indonesia and Iraq. In the U.S.A the financial year begins on the 1st of October. Clearly, different countries have different financial years. We have attempted to find out the reasons for selecting different financial years by different countries.

\section{United States of America}

In United States there was wide diversity in adoption of the financial year. Many governmental organizations employed the calendar year. Some states like Alabama and Maryland used the 1st October - 30th September term as financial year. Other states like Washington adopted 1st April - 31st March as the financial year. But most of the governments - state, local and federal followed the 1st July - 30th June financial years.

The documented dates suggest that between 1789 and 1842, the federal government's financial year was the same as the calendar year. Thereafter from 1844, 30th June was selected as the financial year ending. The rationale behind the change-over was twofold. Firstly, the mainstay of the local and state government revenues was property tax revenue. And property tax was collected in fall when the farmers sold their crops. It would be inconvenient for a fiscal year to begin early in January and wait till nine months for the main source of revenues for the current year. On the other hand, funds would be collected early in the operating year if a JulyJune financial year was adopted. This reason is considered to be more or less obsolete now. The other reason is that the legislatures usually convened in January. And with six months in hand before the financial year began, they could debate and decide on the budget to be adopted. Following a calendar year budget would not have permitted this convenience.

Later by the Congressional Budget and Impoundment Control Act of 1974, the budget year was changed to 1st October - 31st September from the year 1976. This was done to allow the Congress more time to decide and arrive on a budget. Ever since, the federal government has followed the 1st October - 31st September financial year.

The state governments might have a financial year different from that followed by the federal government.

\section{Great Britain}

The earliest known financial year adopted by the Great Britain ended on the 29th of September, corresponding to the Michealmas quarter-day. Thereafter from 1752 till about 1800 , the financial year in Great Britain ended on the 10th of October. The financial year for 1800-01 ended on the 5th of January which corresponded to the usual accounting day in commerce back then. It was in 1832 that the budget was presented for the year to 5th April, 1833. The annual supply grants were voted for the year ending 31st March. But the financial accounts continued to adhere to the 5th January norm until 1854. Thereafter, the Public Revenue and Consolidated Fund Charges Act of 1852 mandated that the Finance Accounts be made up to the 31st of March thereon.

The change in financial year that was effected in 1832 was attributed to the fact that, under the previous arrangement, it was impossible to have the Parliament in session until after the financial year had begun. Post-autumn, it was almost impossible to convene a fresh season 
before the Christmas holidays. What happened therefore was that the expenditures were made before supplies were voted in. Thus the change was apt.

\section{Australia}

Australian colonies used the calendar year as their financial year in the 19th century. This was seemingly because the calendar year was being used as the financial year in Great Britain back then. Even after Great Britain changed the financial year ending to 31st March in 1832, certain Australian states continued to adhere to the calendar year. The change from the calendar year to a financial year ending on 31st March was pioneered by Victoria in 1870. Thereafter, South Australia, Queensland, Western Australia, New South Wales and Tasmania followed suit.

The change was consequent to a consensus of the states, on the fact that, it was greatly inconvenient to get the Parliament together in the months of November or December. This invariably resulted in the delay of having the allocations sanctioned. In consequence, the payments wanted at the commencement of the year were delayed until later. It was acknowledged that, had the Parliament been in session just before the end of the financial year, the inconvenient delays could have been circumvented. The festivity around the Christmas time made the Parliament sessions then, unsuitable. Most of the people desired to head to their homesteads instead of attending to their parliamentary duties. It was also, suggested that working in the winter months was far more fitting than the hot months of summer. Changing the financial year from the calendar year to the June 30th also made sense because industrial work in the country was mostly done between the months of September to March.

These considerations of climate and convenience resulted in Australia adopting the financial year ending on the 30th of June. Ever since, the Australian financial year has spanned over the 1 st of July to the 30 th of June.

\section{Iran}

Iran's financial year follows the Solar Hijri Calendar. It usually begins on the 21st of March and concludes on the 20th of March of the following year. 21st of March corresponds to the 1st day of Farvardin. It is the first month of the Solar Hijri Calendar and the first day of the spring season. Thus, local customs and traditions guide the choice for the financial year.

\section{Afghanistan}

The present financial year in Afghanistan starts from 21st December and ends on 20th December of the following year. It corresponds to the Afghan calendar. Prior to this it used to begin on the 21st of March and close on the 20th of March of the following year. Presumably, the choice of financial year in Afghanistan is governed by local traditions and customs.

A cross-country analysis shows that governments across the globe have no uniform financial year as such. Thus a "global standard" of any kind does not exist. Governments have invariably chosen a date best suited to their convenience.

\section{THE CURRENT ISSUES AND DEBATES IN INDIA}

The first known financial year practiced in India commenced from 1st May till 30th April. This was synchronized with the end of the harvest season in the country, 14th April. Thereafter, Foster and Whiffin (1865) had recommended that the financial year be changed to commence from the 1st of January. Although the Secretary of State deliberated on the recommendation in 1866, subsequently it was decided that 1st April was a better suited date for the commencement of the financial year. This effort was aimed at aligning the Indian financial year 
with that of the British government. The financial accounts and estimates were routinely sent across to England for review. The alignment of 1867 was expected to simplify matters of administration.

Thereafter, numerous suggestions have been made for changing the Indian Financial. The first suggestions for the change came in as early as 1870. In 1984, the L.K. Jha Committee had recommended that the Financial Year be commenced from 1st January, i.e. the calendar year. But the government has maintained status quo on the matter. Financial Year in India continues to span from the 1st of April to the 31st of March. In recent times, the debate has been rekindled by the appointment of a committee by the Ministry of Finance to examine the feasibility of the change in financial year. Dr. Shankar Acharya, former Chief Economic Advisor has been entrusted with the chairmanship of this committee.

\section{The need for a new financial year in India}

The present financial year, 1st April - 31st March, was adopted without taking into consideration local or Indian factors. Thereafter, it has been always argued that the present setting leads to formation of budgets without any knowledge of the 'South-West' and 'NorthEast' monsoons that play an instrumental role in defining the socio-economic nature of the nation. Furthermore, the present financial year is also argued to be inconvenient from the point of view of national culture and traditions, optimum utilization of working season and convenience of administrators and legislators. Various expert committees that were set up over the years have voiced their consensus regarding the change of the Indian Financial Year.

\section{Events leading to the setting up of the L.K. Jha Committee}

The suggestions for change in financial year had come soon after it was adopted in 1867. Thereafter, the Welby Commission in 1900 and in 1908, on the instruction of the Maharaja of Darbhanga the matter had been reconsidered. Further, in 1914, the Chamberlain Commission, formally known as the Royal Commission on Indian Finance and Currency had recommended that the financial year is made to commence either on the 1st of January or the 1st of November. The Commission held that the existing financial year setting was highly inconvenient because the estimates of the budget were prepared without any knowledge of the monsoons. In 1954, the Congress Session at Kalyani had proposed that the financial year begin from 1st July. In their 20th report, the Estimates Committee had proposed that the financial year commence from 1st October. Lastly, the Administrative Reforms Commission (1966) had recommended various alternative dates with separate considerations for each. But government maintained status quo considering that the disadvantages which would arise out of the change would outweigh the advantages.

The National Development Council rekindled the debate in 1981. Subsequently, the Finance Minister in his Budget Speech of 1984 decided to set up an Expert Committee to revisit the matter of changing the financial year.

Consequently, the L.K. Jha Committee was constituted on the 1st of May, 1984. The main considerations concerning bringing about a change in the financial year revolved around information about ensuing monsoons for proper estimation of receipts and expenditures, the optimal utilization of the working season, suitability from the point of view of national accounts and convenience of the Members of Parliament/State Legislatures, in matters of presenting and passing the Budget or touring of the constituencies. Other considerations include the taxation systems, crop periods and desirability of achieving uniformity in accounting years followed by other organizations like the financial institutions, the cooperatives, etc. 


\section{Basic scheme suggested by the L.K. Jha Committee}

On the outset it was agreed that the financial year must correspond to the Gregorian calendar instead of the Hindu calendar. It would simplify matters because the former was used by both, the government as well as the business community. Further, the financial year was to commence from the beginning of either quarter. That narrows down the alternatives to 1st January, 1st April, 1st July and 1st October. Most of the countries across the world as well as the organizations within the domestic economy followed either of these alternatives. Lastly, there was consensus on the fact that the centre and state should implement the same financial year. The deliberations in the Jha committee report are discussed below.

\section{Considerations of the Monsoons}

The Jha Committee Report held that agriculture being the mainstay of the Indian economy had made monsoons inevitably important to the framing of the budget. And in the existing financial year set up, the budget was prepared without proper knowledge of the monsoons.

The Budget Circular issued to the Ministries/Departments by the Ministry of Finance in September marks the beginning of the Budget process. These ministries thereafter, put forth their estimates of receipts and expenditures after having engaged in several pre-budget discussions, assessment of revenues etc. The final estimates are arrived at by the end of January. This implies that the estimates are calculated without proper knowledge of the Monsoon behavior. Now, Indian Budget, inevitably, has to account for the quality of monsoons when estimating the receipts and expenditure for the coming year. The Budget is not just an account of estimates receipts and expenditure flow for the coming financial year. It also portrays the government's stance on the policies for allocation of scarce resources. This meant that the impact of a bad monsoon on the budget is not just on the account of a drop in the revenues. An ensuing drought might entail additional expenditure on drought relief, higher subsidies etc. Considering that the budget is instrumental in effectively addressing the socioeconomic needs of the nation, the report argues that the present financial year hinders the government's responsiveness to it. Thus, the committee urged rightly that the financial year be commenced at a time when the monsoons for the year have been correctly assessed.

The report suggests that calendar year turns out to be favorable in this context. The existing financial year set up puts the government in a spot where fiscal allocations are decided and investment plans are charted in the ignorance of the monsoon rains. But in case the financial year commenced on the 1st of January, the budgetary process could be made to start from October. In October, the performance of the monsoons would have been by and large assessed.

\section{Considerations of the Utilization of Working Season}

The working season in India begins post South-West monsoons. The South-West Monsoons span over July to September invariably. The working season thus begins in October and extends up to the next 8 to 9 months till the onset of the next South-West Monsoons. The report asserted that sluggish administration leads to under-utilization of the working season. The allocations made in the budget take time to reach the executive agencies. The works programmes get held up in many areas, for as much as the first three months. Thus, the effective working season is reduced to about six months. Three months are lost to the South West Monsoons and another three to the budgetary process. The suggestion here is to begin the financial year at a time such that it coincides with the South-west monsoons. Alternatively, resolving the lag in the budgetary allocation process could also resolve the issue. 


\section{Considerations of the National Accounts}

Although the National Accounts are published for the financial year, they are based on data which are compiled on the basis of either of the financial year, the agricultural year or the calendar year. It was believed that having a single accounting period for the data would be advantageous. Crop periods are different for different crops. The crop statistics correspond to the agricultural year which comprises of the rabi and kharif crop harvests. The cooperative year is linked to the agricultural year stretching across July - June. The agricultural statistics pertain to the agricultural year and not the present financial year setting. The Central Statistical Office (CSO) adjusts the agriculture production estimates in the four quarters of the financial year on prorata basis to that of the total production in the financial year. This ensures consistency between the quarterly and annual, GDP estimates. Although, it may be difficult to completely eliminate the variations arising from difference in data collection periods, these fail to pose any significant limitation to the quality or consistency of data. The data pertaining to non-agricultural statistics, particularly the industrial statistics mostly follow the financial year.

In view of the difficulties in synchronizing the agricultural statistics with the financial year, the report suggests that a calendar year would ease the arrangement. It would also be in line with the United Nations statistical reporting practice.

\section{Considerations of Legislator's Convenience}

The legislators have the responsibility of touring their constituencies. The report perceived that the existing financial year left the legislators with the inconvenient rainy season for the purpose of touring their constituencies. Thus the suitability of the new financial year from this point of view was to be reviewed.

\section{Considerations of Tax Laws}

The impact of the change in financial year would be most felt over the transitional period, the report assessed. But it was widely acknowledged by the Union Ministry of Finance and the State Governments that the changes necessitated in the tax laws, during the transitional period, would not be extreme. Thus with reasonable adjustments, the change-over in the financial year could be conveniently implemented irrespective of the choice of the date.

After deliberations on the various listed matters, the States across the nation were called upon by the Jha Committee to put forth their views. The view point of the states was of utmost importance because the financial year was to be same for both the governments, central and state. The response received after comprehensive discussions held amongst the Chief Ministers and Finance Ministers of various states and the Chairman and Member -Secretary of the committee, clearly pointed out towards an uncontested eagerness for a change.

A significant number of states favored the adoption of the calendar year. The rationale for it was that there would be significant advantages from the point of view of the impact that the monsoons had on the economy. Some states also pointed out that a January-December financial year would lead to fragmentation of the working season. But the committee contested that the issue could be resolved by introducing reforms in administrative and financial procedures. 
The following table summarizes the views of the states, registered back then.

\begin{tabular}{|c|c|c|c|}
\hline $\begin{array}{l}\text { ALTERNATIVE } \\
\text { DATES }\end{array}$ & $1^{\text {ST }}$ PREFERENCE & $\begin{array}{l}2^{\text {nd }} \\
\text { PREFERENCE }\end{array}$ & RATIONALE \\
\hline 1st January & $\begin{array}{l}\text { Gujarat, Himachal Pradesh, } \\
\text { Maharashtra, Jammu \& } \\
\text { Kashmir, Karnataka, Manipur, } \\
\text { Haryana, Rajasthan, Uttar } \\
\text { Pradesh }\end{array}$ & $\begin{array}{l}\text { Andhra } \\
\text { Pradesh, } \\
\text { Bihar, Orissa, } \\
\text { Sikkim, Tamil } \\
\text { Nadu }\end{array}$ & $\begin{array}{l}\text { Clear idea about the monsoons. } \\
\text { With proper administrative } \\
\text { reforms, interruption in the } \\
\text { execution of works programme } \\
\text { could be minimized. }\end{array}$ \\
\hline 1st July & $\begin{array}{c}\text { Haryana, Madhya Pradesh, } \\
\text { Meghalaya, Punjab, Andhra } \\
\text { Pradesh, Bihar, Orissa, } \\
\text { Nagaland, Tripura }\end{array}$ & Kerala & $\begin{array}{l}\text { Happened to be the agricultural } \\
\text { year, cooperative year. } \\
\text { Minimizes the interruption in } \\
\text { the execution of the works } \\
\text { programme. }\end{array}$ \\
\hline 1st October & & $\begin{array}{l}\text { Madhya } \\
\text { Pradesh }\end{array}$ & $\begin{array}{l}\text { Clear idea about the monsoons } \\
\text { is available by this time. }\end{array}$ \\
\hline Status Quo & $\begin{array}{c}\text { Sikkim, Kerala, Assam, Tamil } \\
\text { Nadu }\end{array}$ & & $\begin{array}{l}\text { Not that April-May had any } \\
\text { significant advantage. } \\
\text { Apprehensions about } \\
\text { dislocation possible on account } \\
\text { of adjustment in procedures, tax } \\
\text { laws etc. }\end{array}$ \\
\hline
\end{tabular}

Source: L.K. Jha Committee Report.

Keeping in view several advantages arising from the change-over, the committee recommended that the financial year be synced with the calendar year. The government, however, decided to maintain status quo on the financial year. The government maintained that there would emerge only marginal advantages from the change-over. Further, the change would disrupt the data collection procedure which might take a long time to return to normalcy. Lastly, the government argued that a changeover would entail extensive amendments to taxation laws and systems and other administrative machinery would get diverted to the problems of transition.

\section{The Present Scenario}

Thirty one years have passed since the recommendations of the L.K. Jha committee were rejected by the government. The keen interest that the government has shown in the matter of the change-over recently, calls for a return to the considerations governing the choice of the financial year in the Indian context.

Recently, Niti Aayog has issued a report on the need for changing India's Financial Year. It has reiterated the suggestions of the Jha Committee Report. The details of the report are discussed below.

\section{On the Monsoons}

The report believes that although the contribution of agriculture to the Gross Domestic Product has witnessed a secular decline, it continues to play a significant role through its 
forward and backward linkages in the economy. And therefore, monsoons continue to be instrumental to the estimation of receipts and expenditures of the government.

The problem with the existing financial year is that by the time the fresh allocations are sanctioned, the impact of the previous South-West Monsoon is already over and by the time allocations reach the executing authorities, the next South-West monsoon is about to begin. Thus the policy measures in the budget are more 'reactive' in nature than 'proactive'.

$54 \%$ of Indian agriculture is still rain-fed. The moisture retained by the soil on account of a healthy monsoon greatly enhances the production of crops. Further, a good monsoon contributes to various sources of water like reservoirs, ground water, wells, ponds etc. An erratic monsoon generally hits agriculture sector by the way of reduced crop outputs.

Moreover, almost 40\% of the entire rural households in the country depend on agriculture for their livelihoods. Thus, the Agriculture sector accounts for considerable work force employment in the country. Agriculture has significant linkages with the headline inflation as well. Given the multifold significance of agriculture, it is the focus of all political attention.

The monsoons in India are highly unpredictable. Even with the best of technological advancements that have happened in the recent times, one can only hope to get an approximation at best. Thus, they agree with the Jha committee report in changing over to a January-December Financial year for the sake of better information on the monsoon behavior, given its crucial nature.

\section{On the Working Season}

It had been argued earlier that the January- December financial year will lead to fragmentation of the working season. The report states that slowdown in the developmental and other activities on account of time-lag in budgetary process have been reduced to great extent. The Monsoon does halt the construction works for certain duration. But it will continue to do that irrespective of the choice of financial year. The procedural improvements implemented by the government in recent times, have addressed the issue of sub-optimal utilization of the working season. And therefore, the calendar year poses no serious hindrance to the consideration of optimal utilization of working season.

\section{On National Account Statistics}

The report elaborates that there is no reason to doubt that the change in the financial year to any other time would be disruptive of the order of collection of national statistics. The overarching concern is to be able to capture the two harvests, rabi and kharif crops, over the year. And that continues to be feasible in case a change in financial year was effected. The matter was agreed upon by the Central Statistical Office (CSO). Further, the CSO continues to be in favor of implementing a calendar year for the purpose of collection and compilation of data as it is in line with the UN Statistical Office practice.

\section{On Considerations of International Practices}

A cross-country analysis shows that governments across the globe have no uniform financial year as such. Thus a "global standard" of any kind does not exist. Governments have invariably chosen a date suited to their convenience. But what does exist in common is the fact that almost all the governments choose the beginning of a quarter as the start date of their financial year. And there appears to be a preference in opting for the calendar year as the financial year. 
Most of the Asian countries barring Japan, Thailand, Pakistan and India have adopted the calendar year as their financial year. In South-Asia Indonesia, Philippines, Malaysia, Vietnam etc. have adopted it too.

Furthermore, in most of the countries the Tax year coincides with the calendar year. Thus, many businesses based out of Europe and America, follow the calendar year for their financial accounting purposes.

It is reasonable therefore to assume that the calendar year is the most widely accepted choice for financial year, for the governments and the businesses alike.

\section{On Legislator's Convenience}

With the improvement in the overall infrastructure and connectivity in the country in the last few decades, the constituencies are accessible to the MPs and legislators all throughout the year now. Thus, the consideration of the Legislator's Convenience can be delinked from the question of the financial year. Similarly, weather related inconvenience to the legislators in terms of presenting and passing the budget have also been side stepped.

Having said that, neither does the present financial year doesn't bring any particular inconvenience to the legislators nor will a new financial year cause any particular discomfort to them.

\section{On Considerations of National/Local Traditions}

In view of the rich cultural and traditional diversity in India, a variety of alternatives would emerge for the financial year. It could be either linked to the "New Year" of the Hindu Calendar. But in context of modern times, a considerable number of citizen associate New Year with the 1st of January.

Alternatively, the new financial tear could be linked to the "harvest festivals". The options could be Onam or Pongal/Makar Sankranti. Lastly, it could be linked to the Diwali as the festival is celebrated across the nation, alike. Given the various possibilities, it is difficult to choose one. It is wise rather not to engage in the Hindu calendar for the financial year.

Choosing the calendar year as the financial year, fares better in this context as well because it is reflective of the modern practices of the youth of the nation.

The Niti Aayog's report on the need for changing India's financial year revisits all the considerations made by the L.K. Jha Committee report and advocates its views. It suggests that the government should switch the financial year to the calendar year.

\section{AUTHOR'S SUGGESTIONS}

We differ significantly from the stance of the Niti Aayog's report. We suppose that the gains believed to be materializing from the change-over of the financial year are farfetched. Over the many years, since the Jha committee's recommendations, numerous changes have unfolded.

Technology has witnessed rampant adoption in India, in the cities, as well as the hinterlands. An outcome of technological progress, we indeed have a greater clarity of the monsoons and their behavior, if not an exact estimate. Rainfall situation is routinely monitored by a wide network of observatories. The monitoring is done over spatial and temporal scales over the country. The ambiguities associated with a drought or flood like situation have been mitigated 
by the early warning indicators though scientific measures. The reactive and relief centric approach towards droughts and floods has been done away with. The focus of the governments, state and central, is on the integrated management emphasizing on prevention, mitigation and preparedness, which has resulted in minimizing loss of lives and livelihoods on account of a drought or flood. At present, redesigning of strategy for agriculture to reduce drought vulnerability and increasing farm income through higher investment in irrigation, access to institutional credit, provision of quality inputs like seeds, fertilisers and pesticides have been put in place.

Some of the States in India have started preparing a separate Agriculture Budget to care of Agriculture sector in a comprehensive manner. .

The fiscal stress to the government in dealing with droughts was because relief measures were given precedence over the mitigation measures. This in turn, put enormous strain on the state budget dismissing developmental plans. But the states in present times have moved on to become comprehensively prepared for untoward situations like drought. The State Disaster Response Fund, supplemented by the National Disaster Response Fund in case of acute emergencies, is a non-lapsable fund provisioned to meet immediate relief expenditure to the victims of drought, cyclone, flood and various other contingencies. Drought resilience is strengthened further by provisioning of additional days of work under MNREGA to drought affected households, diesel subsidy scheme for farmers in affected areas, enhancement of ceiling on subsidy, interventions for saving perennial horticulture crops, implementation of additional fodder development programme, flexible allocation under Rashtriya Krishi Vikas Yojana and other centrally sponsored schemes and framing of a crop contingency plan.

Additionally, introducing participatory democracy, laying out location specific crop contingency plans and focusing on long term drought proofing programmes e.g. watershed development, water harvesting etc. has gone a long way in addressing the woes of the unpredictable, insufficient monsoons.

Further, various schemes like Pradhan Mantri Krishi Sinchayee Yojana (PMKSY), Krishonnati Yojna aim at extending irrigation coverage and improving crop husbandry ensure that rural incomes are safeguarded and rural development is strengthened. Lastly, the Pradhan Mantri Fasal Bima Yojana scheme has been introduced to make crop insurance easily available to farmers.

Thus, the crucial role that the monsoons used to play in the framing of and in deciding the impact of the budget seems to be blown up in today's times. The government has exhaustively attempted to blunt the exposure of agriculture sector output to the erratic monsoons. The impact of a bad monsoon is almost always taken into account and factored in while allocating fund while framing the budget.

The governments, state and central, are no longer in a limbo. They have dynamic research and analysis teams. Factoring in of changing circumstances is fast and responsive. The focus is on completion of on-going major, medium and minor irrigation projects along-with installation of Mega Lift, Shallow and Deep Bore Wells and Micro Irrigation facilities to optimize water use efficiency.

Steps have been taken for crop diversification from cereals to pulses and millets, revitalising the extension system for transfer of advanced technology, strengthening of market linkages through financing, storage and transportation, risk mitigation and value addition. 
Thus, in view of the present setting, the role of monsoons in deciding the financial year is at best passive, if not redundant.

In context of considerations of the utilization of working season, significant changes have become common place. The State governments have introduced the Integrated Financial Management System (IFMS) with the intention of automating and computerizing the budget execution and account operations. Under IFMS, the major initiatives taken by State Governments include Electronic Payment System, e-Government Receipt Accounting System, State Public Procurement Portal, Integrated Human Resource Management system and few others. These systems ensure real time transfers. The IFMS is entirely web based facilitating state wide financial transactions and efficient monitoring. The previously required manual checks of receipts and their expenditures have been done away with. Now the treasury and the Finance Department have a clear picture of the total budget expenditure on a daily basis. This ensures seamless data flow across the system, so that the implementing authorities make wellinformed decisions.

Furthermore, the centralized electronic payment channels ensure that the funds reach the implementing authorities in real time. Thus, the time-lag that plagued the system and caused works programmes to get delayed in the first few months of the financial year have been successfully circumvented. However, the slowdown in the construction works on account of monsoons cannot be avoided.

The collection of national statistics as on date doesn't show any signs of inconvenience. Although, it is not aligned with the UN Statistical office practice, the existing practice doesn't warrant any immediate redesign. Likewise, the consideration of the financial year not being in sync with the local or Indian customs can be ignored. Owing to the diversity of the cultures and traditions in India, it is best not to engage in choosing one of the many possible alternatives.

With the great strides of development that transport and communication have taken in the recent past, the convenience of the legislators in touring their constituencies is no longer a concern. Fair weather roads and telecommunication connectivity ensures that they have desirable access to their constituencies all-round the year.

Besides, India is on the threshold of changing over to a multi-year budget framework. Many states are examining the feasibility of implementing a medium term fiscal strategy. In these changing times, the considerations that at one point played a decisive role in the choice of a financial year in India are losing relevance.

\section{CONCLUSION}

The detailed discussion above points out that the need for changing the current financial year is avoidable. The responsiveness of the Government is adequate as the uncertain nature of monsoons are anticipated and factored in while formulating budgets.

The importance of monsoons in agriculture and thereby the lives of several people employed in agriculture is undeniable. But modest understanding of the monsoon behavior has considerably improved the investment planning and budgetary allocation procedures. Over the years, the quality of planning has considerably improved and states are abreast with advancements in technology, thereby bringing about tremendous transformation in the development of the rural populace. 
A change in financial year entails engaging in making amendments to taxation laws and systems and financial procedures concerning authorization of expenditure. In consequence, the administrative machinery would have to be diverted towards these problems of transition. Instead, it would be more judicious to redirect these administrative systems towards the successful implementation of the Goods and Services Tax (GST. Successful implementation will raise the tax efficiency of both national and sub-national governments. The implementation of GST calls for the standardization of systems and procedures across the country. This includes the tax payer registration system, tax reforms, tax reporting periods, taxpayer identification numbers, cross border trade information systems and IT systems. The overhaul of the entire machinery would require massive training efforts, at the central and the state level. So, a diversion of administrative machinery to this effort would be favorable, given the potential of the GST to bring in many economic benefits.

Furthermore, the government is mulling over switching to a multi-year budget framework in the near future. The multi-year budget is unique because it allows long term interlinking of current year budgets with future years' expenditure requirements. Thus, it would provide a platform whereby perennial fiscal problems could be resolved by matching the government's expenditure commitments to the resources available. It will improve long-range and strategic planning. Introducing the medium term approach to budget formulation would help prioritizing expenditure commitments in line with the fiscal strategies. This would improve resource allocation. Moving away from the annual budgets would necessarily blunt the impact of a choice of a particular financial year.

Considering the recent developments in the economy, we believe that the need for a change in the financial year of India is escapable. Thus, maintaining status quo instead of engaging in the cumbersome task of changing the financial year appears reasonable.

\section{Bibliography}

Ambedkar, B. (1925). The Evolution of Provincial Finance in British India. King.

Arndt, H. (1963). The Financial Year. The Australian Quarterly, 35 (2), 51-56.

Debroy, B., \& Desai, K. (2016). Need for Changing India's Financial Year - A Discussion Note. New Delhi: Government of India.

Bibliography Ambedkar, B. (1925). The Evolution of Provincial Finance in British India. King.

Arndt, H. (1963). The Financial Year. The Australian Quarterly, 35(2), 51-56.

Debroy, B., \& Desai, K. (2016). Need for Changing India's Financial Year - A Discussion Note. New Delhi: Government of India.

Jha, L. (1985). Report of Shri L K Jha Committee on the change in Financial Year. New Delhi: Governnment of India. Misra, B. (1942). Indian Federal Finance.

N.C.Lahiri, M. a. (1992). History of the Calender in different Countries Through the ages. New Delhi: CSIR.

Prasad, M. P. (2016). Financial Year (FY) or Fiscal Year. New Delhi: Arthapedia.

Thomas, P. (1939). The Growth of Federal Finance in India.

Jha, L. (1985). Report of Shri L K Jha Committee on the change in Financial Year. New Delhi: Governnment of India. Misra, B. (1942). Indian Federal Finance.

Thomas, P. (1939). The Growth of Federal Finance in India. 